\title{
NOTICIAS FALSAS Y LIBERTAD DE EXPRESIÓN E INFORMACIÓN. EL CONTROL DE LOS CONTENIDOS INFORMATIVOS EN LA RED ${ }^{1}$
}

\author{
CRISTINA PAUNER CHULVI \\ Profesora Titular de Derecho Constitucional \\ Universitat Jaume I
}

\begin{abstract}
SUMARIO
I. Introducción. II. La circulación de la información en la actualidad. Los mecanismos de generación de la opinión pública. III. La reacción de la Unión Europea y los Estados miembros ante la proliferación de las noticias falsas. IV. Las redes sociales ante el fenómeno de las noticias falsas. Soluciones propuestas. V. Los sistemas de filtrado y las garantías constitucionales de la libertad de expresión e información. VI. Conclusiones.
\end{abstract}

\section{INTRODUCCIÓN}

El inesperado desenlace de acontecimientos recientes como el fracaso del referéndum por la paz en Colombia, la victoria del Brexit en Reino Unido o, muy significativamente, la victoria de Donald Trump en las elecciones presidenciales en Estados Unidos ha provocado un intenso debate sobre la influencia de las noticias falsas en aquellos resultados.

La existencia de noticias falsas no es, evidentemente, ninguna novedad puesto que la difusión de información sin contrastar o, más llanamente, el ejercicio de mal periodismo se corresponde con lo que tradicionalmente se ha llamado manipulación o amarillismo. Pero con la irrupción de las tecnologías de la información y de la comunicación el fenómeno ha adquirido una nueva dimensión. Si, por un lado,

1 El presente trabajo se enmarca en el proyecto de investigación sobre la reforma del sistema europeo de protección de datos financiado por el Ministerio de Economía y Competitividad (DER2015-63635-R) y se ha realizado en el curso de una estancia de investigación en el Centre for Commercial Law Studies de la Universidad Queen Mary (Londres). 
los nuevos medios de comunicación social (blogs, redes sociales, páginas web, etc.) proporcionan un apoyo extraordinario para optimizar la comunicación humana y facilitar el acceso a grandes cantidades de información, por otro lado, también procuran un alcance universal a las noticias inventadas o falsas contraviniendo el carácter funcional del derecho a la información como derecho directamente vinculado con la garantía de una opinión pública libre². Así, la diferencia fundamental entre la difusión de noticias falsas publicadas en medios tradicionales y las que se publican en páginas web es que estas últimas alcanzan gran impacto y viralidad porque cuentan con las redes sociales para difundirse globalmente.

Las noticias falsas provienen de sitios ficticios diseñados para parecer fiables que producen títulos sensacionalistas para atraer al lector. La polémica creada por estas noticias maliciosas implica principalmente a las fuentes o portales que las crean pero también a las redes sociales que ayudan a su propagación viral y a las plataformas de publicidad que las financian.

Aunque en mucha menor medida, tampoco los medios de comunicación tradicionales escapan de algunos ejemplos de difusión de noticias inveraces o no contrastadas cuya aparición suele relacionarse ahora con la crisis estructural del periodismo como modelo sostenible. Desde hace aproximadamente una década, se ha producido un cambio extraordinario en el diseño de negocio de la prensa que no rentabiliza su tradicional patrón publicitario y se enfrenta a nuevas exigencias del público, distribución y comercialización. Y las grandes empresas de comunicación están respondiendo a una caída generalizada de anunciantes y suscriptores con recortes de personal o reconfiguraciones de plantilla más o menos drásticas.

Esta transformación también ha alcanzado a los nuevos modos de producción narrativa de la prensa basada ahora en la rapidez o casi instantaneidad informativa. Con el advenimiento del entorno digital y la necesidad de una información permanentemente actualizada se ha quebrado la precisión que requiere la elaboración de las noticias, una de las condiciones básicas para ofrecer información de calidad y sin errores. Los diarios trabajan contra reloj para ser los primeros en informar sobre un acontecimiento y lanzan alertas de noticias en primer lugar porque esto les asegura un mayor tráfico de visitas aunque después tienen que elaborar la crónica «que ya no es un producto acabado fruto de una elaboración profesional independiente, sino un proceso público en constante mutación que debe convivir con multitud de discursos no profesionales difundidos por distintos cauces y plataformas» ${ }^{3}$.

2 La vinculación entre la libertad de expresión e información y una democracia funcional está firmemente consolidada en la jurisprudencia constitucional y europea. Sirvan, por todas, la STC 6/1981, de 16 de marzo y la STEDH, de 24 de mayo de 1988, caso Müller y otros.

3 SUÁREZ VILLEGAS, J. C. y CRUZ ÁlVAREZ, J., «Problemas éticos de la instantaneidad informativa en el entorno digital», en I Congreso Internacional de Comunicación y Sociedad Digital, B. Lloves y F. Segado (coords.), 2013, p. 11. Sobre el cambio en el proceso de elaboración de la información, puede verse por todos BROCK, G., Out of Print: Newspapers, Journalism and the Business of News in the Digital Age, Kogan Page, Philadelphia, PA, and London, UK, 2013. 
El peligro de las noticias falsas es que crean una sociedad que no es capaz de ponerse de acuerdo sobre hechos básicos lo que impide construir una democracia funcional. La desinformación afecta directamente a los fundamentos de las sociedades democráticas que se construyen sobre la presunción de que sus ciudadanos toman decisiones informadas en el momento de acudir a votar. Gracias a la información que los ciudadanos recibimos acerca de los asuntos públicos, acerca de la labor de nuestros representantes o del trabajo que desarrollan las instituciones públicas podemos formarnos una opinión sobre los mismos y ejercer un control sobre su gestión. Pero este objetivo puede verse truncado si la información es falsa, engañosa, en una palabra, inveraz. Solo la información veraz y sobre materias de interés general, por los asuntos y las personas que en ella intervienen, contribuye a la formación de la opinión pública, sirve como mecanismo de control democrático y puede gozar, por tanto, de protección jurídica.

En su libro A Preface to Democratic Theory, Robert Dahl enumeraba una lista de ocho requisitos para crear una mayoría decisiva. Tras identificar el sufragio en los cuatro primeros requisitos, la quinta condición que presenta Dahl es que «todos los individuos posean una información idéntica sobre las alternativas existentes» ${ }^{4}$. Así, la apertura a la entrada de flujos no controlados de información a través de Internet es una buena noticia frente al poder que, en su concepción tradicional, se le asignaba a la prensa como determinante de la agenda política y puede afirmarse que el mundo se ha democratizado extraordinariamente gracias a la accesibilidad a nuevos canales por los que desarrollarse. Pero esta apertura también tiene un ángulo negativo ya que el consenso debe construirse sobre unas bases comunes y el esparcimiento de la desinformación puede hacer imposible ese mínimo compartido. Si los colectivos construyen su propia realidad no se podrá llegar a acuerdos.

La gravedad de esta amenaza y la magnitud del fenómeno de las noticias falsas ha puesto en alerta a los medios de comunicación y los poderes públicos y es motivo de preocupación a nivel mundial. Así, algunos gobiernos europeos han presentado diversas medidas para contrarrestarlo. Alemania, Reino Unido o Francia ya han puesto en marcha diversas iniciativas con el objetivo de protegerse frente a la difusión masiva de noticias falsas. Conscientes del limitado impacto y eficacia que una lucha a nivel nacional contra las noticias falsas puede tener en la época de la globalización, el ámbito de actuación se ha ampliado a la Unión Europea. Desde las instituciones comunitarias se ha lanzado una llamada de colaboración a las grandes empresas tecnológicas para frenar la propagación de informaciones fraudulentas que inundan la Red y se ha reclamado un compromiso similar al seguido en la lucha contra la propagación de mensajes de odio a través de las redes sociales 5 . En el ámbito internacional, la ONU ha expresado su

4 DAHL, R., A Preface to Democratic Theory, The University of Chicago Press, Chicago-Londres, 1956, p. 71 .

5 Nos referimos al Código de conducta contra el discurso ilegal del odio a través de Internet, aprobado el 31 de mayo de 2016, como una de las iniciativas derivadas de la Estrategia para el mercado único digital de la 
preocupación por el tema en una reciente Declaración conjunta sobre Libertad de Expresión y Noticias Falsas, Desinformación y Propaganda ${ }^{6}$, en la que declara su inquietud porque la desinformación y propaganda se implementen para confundir a la población e interferir en su derecho a recibir información variada y a formarse su propia opinión.

Sin embargo, los intentos por atajar las noticias falsas y las peticiones de aumentar la regulación sobre el contenido en línea para impedir su tráfico plantean numerosas dudas acerca de cuál debe ser la respuesta democrática a la desinformación. ¿Qué son las noticias falsas? ¿Cuándo una información sesgada pero legítima se transforma en propaganda y mentira? ¿Quién va a vigilar el contenido de la información que circula por las redes? ¿Qué responsabilidad tienen los buscadores y las redes sociales? ¿Es viable un algoritmo para erradicar las noticias falsas sin impedir la recepción de las noticias auténticas? ¿Qué pautas se utilizarían para discriminar una información de la otra? ¿Es el criterio de la «verdad» el adecuado? ¿Cómo deben responder los gobiernos a este fenómeno? ¿Puede resultar más útil a la democracia que la gente sea la encargada de juzgar y escoger la información que reciba, sin participación de un tercero?

En principio, la idea de que sobre las empresas proveedoras de servicios online, como una red social, recaiga parte de la responsabilidad de filtrar noticias parece peligrosa porque somete el acceso a Internet y a sus contenidos a parámetros empresariales. Del mismo modo que decidir que esta función la ejerza un gobierno puede conducir a que se califique como una forma de censura y llevar a la instauración de una especie de ministerio de la verdad.

Por último y antes de abordar el análisis de todas estas cuestiones debemos realizar una aclaración sobre el significado de las dos expresiones que, habitualmente, se están utilizando por los medios y la doctrina para aludir a la problemática presentada. Nos referimos a los enunciados «noticias falsas» $\mathrm{y}$ «posverdad» ${ }^{7}$. Estos neologismos mantienen una relación cercana y complementaria ya que, aunque son términos que aluden a realidades distintas, muy habitualmente se da entre ellos una correlación temporal.

Noticias falsas significa informaciones publicadas deliberadamente en medios digitales que no han sido comprobadas ni verificadas, carecen de fuentes identificadas y sin supervisión de un editor. Su objetivo es influir en la opinión pública y crear inseguridad, sospechas, desestabilización para apoyar o desacreditar o, a veces,

\footnotetext{
Comisión Europea. Disponible en http://ec.europa.eu/justice/fundamental-rights/files/hate_speech_code_of_ conduct_en.pdf. Ver nota a pie núm. 20.

6 Declaración conjunta sobre Libertad de Expresión y Noticias Falsas, Desinformación y Propaganda, de 3 de marzo de 2017, adoptada por los relatores especiales sobre la libertad de expresión y opinión de la ONU, la Organización de Estados Americanos (OEA), la Organización para la Seguridad y Cooperación en Europa (OSCE) y la Comisión Africana de Derechos Humanos. Disponible en http://www.ohchr.org/SP/NewsEvents/ Pages $/$ DisplayNews.aspx?NewsID $=21287 \&$ LangID $=$ E.

7 SANTAMARÍA, P., «Antropología social: La diferencia y relación entre posverdad y noticias falsas», 16 de enero de 2017.
} 
simplemente diversión. En última instancia, son un medio para obtener seguidores, perfiles y usuarios de redes sociales para alentar un movimiento, un interés económico o de marca o a una persona. Los canales que distribuyen esta información tienen apariencia de periódicos lo que contribuye a crear confusión en un intento de aprovecharse de la credibilidad que acompaña a muchos medios profesionales de comunicación digital.

Por su parte, posverdad es aquella «circunstancia en que los hechos objetivos influyen menos en la formación de la opinión pública que los llamamientos a la emoción y a la creencia personal» según el Diccionario de Oxford que la eligió como palabra del año en 2016 y que, en diciembre de 2017, ha sido registrada en el Diccionario de la RAE. Es un elemento disruptivo y perturbador que produce un efecto desestabilizador y una respuesta irracional en la sociedad. En este sentido, el término ha venido reflejando que aquello que las personas sienten ante un estímulo, sus emociones respecto de una idea o de un líder, o sus sensaciones subjetivas influyen de una forma más efectiva en la toma de sus decisiones que los datos y estadísticas objetivas o los hechos comprobados siendo más importantes para ellos que la verdad ${ }^{8}$. Lo que cuenta como «hecho» es simplemente la visión de alguien que siente que es cierto o verdad.

Si comparamos ambos conceptos advertimos, en primer lugar, que los sujetos que elaboran cada discurso son distintos ${ }^{9}$ y el foco se traslada desde el emisario de una información falsa bien sean políticos, medios de comunicación u otros usuarios al receptor que es la opinión pública la que, movida por creencias y emociones en lugar de por argumentos, construye su posverdad. Entendemos, en segundo lugar, que solo en el fenómeno de las noticias falsas puede el mundo jurídico hacer aportaciones útiles ocupándose de analizar algunas de sus derivadas: el proceso de creación y autoría de las noticias falsas, su incidencia en el derecho a la información, las medidas arbitradas para su control y eliminación y los riesgos de esas propuestas.

\section{LA CIRCULACIÓN DE LA INFORMACIÓN EN LA ACTUALIDAD. LOS MECANISMOS DE GENERACIÓN DE LA OPINIÓN PÚBLICA}

El análisis del fenómeno de la difusión de noticias falsas debe partir de la identificación de dos sujetos que intervienen en su propagación. En primer lugar, las plataformas o sitios web que crean esas noticias falsas y, en segundo término, las redes sociales que contribuyen a su difusión viral.

Por lo que se refiere a los sitios web, gran cantidad de noticias falsas son originariamente fabricadas por spammers que pretenden engañar a los usuarios de la

8 AMÓN, R., «Posverdad, la palabra del año», El País, 17 de noviembre de 2016.

9 MÁRQUEZ GUERRERO, M., «El trasfondo cínico de la 'posverdad'», Público, 11 de diciembre de 2016. 
Red y lucrarse de ingresos publicitarios por cada clic que hagan esos usuarios. Se trata de falsos periódicos o páginas con apariencia informativa que actúan deliberadamente cuando publican bulos o propaganda pretendiendo ser noticias reales. En puridad, la manipulación fue, en un primer momento, la principal motivación de las páginas creadoras de noticias falsas pero este objetivo pasó a un segundo plano cuando se reveló como un negocio muy rentable porque el elevado número de visitas producía cuantiosos beneficios gracias a la inserción publicitaria.

En una segunda fase, la viralización de esas noticias falsas se produce a través de las redes sociales como Facebook o Twitter en lo que se ha venido a bautizar como «cascada informativa». Precisamente, las páginas de noticias falsas tratan de atraer a esas redes sociales para desviar hacia ellas el tráfico de Internet, amplificar su efecto y aprovechar sus servicios de publicidad con los que obtener cuantiosos ingresos. En una deriva consumista del negocio de la información, la nueva medida de valor de estos medios es, por tanto, la viralidad en lugar de la veracidad o la calidad. Hoy en día no importa si una noticia no es cierta, lo único que realmente importa es que la gente teclee sobre ella. Así, en la actualidad, el control sobre la distribución de las noticias ya no está en manos de los medios de comunicación sino de las redes sociales que son las que las seleccionan y filtran las informaciones mediante algoritmos y plataformas que son complejas, opacas e impredecibles ${ }^{10}$.

En la sociedad de la información, el consumo de noticias en una gran parte de la población no es el fruto de una búsqueda de información en los distintos medios de comunicación sino que hoy la gente consume noticias desde su feed de Facebook, Google u otras redes sociales que las escogen en función de los datos que poseen de sus usuarios - básicamente, el flujo de información seleccionado por amigos, contactos y allegados- y procesan por algoritmos secretos. A través de estas fórmulas se «controla» la información que consumen los usuarios de las redes sociales. En un sentido clásico, las redes sociales no deciden lo que cada individuo lee ni las noticias que se publican en los medios pero cuando una plataforma se convierte en la fuente dominante de acceso a la información — que es lo que ha ocurrido con Facebook rebautizado como el periódico del siglo XXI-, los medios de comunicación se adaptan a sus pautas y confeccionan sus noticias sobre el modo de trabajo de la red social ${ }^{11}$. La prueba evidente de la influencia de Facebook en la prensa es la sacudida que acompaña a cualquier cambio en el algoritmo que selecciona las noticias y que amenaza con reducir las visitas recibidas. Esto contradice la idea inicial de una red

10 El estudio de los algoritmos y su influencia en el mundo de la información es un ámbito poco desarrollado en España pero cuenta con innumerables estudios en la doctrina comparada, especialmente, la anglosajona y norteamericana. Entre los estudios más recientes se recomienda KIRLEY, E. A., «The robot as cub reporter: law's emerging role in cognitive journalism», European Journal of Law and Technology, 7/3, $2016 \mathrm{y}$ WAGNER, B., «Algorithmic regulation and the global default: Shifting norms in Internet technology», Etikk i praksis. Nord J Appl Ethics, 1, 2016, pp. 5-13.

11 VINER, K., «How technology disrupted the truth», The Guardian, 17 de julio de 2016. 
mundial abierta, diversa y descentralizada siendo sustituida por plataformas que centralizan la información, cerrándose incluso a enlaces externos.

Si nos preguntamos acerca de los motivos que llevan a esa aceptación y verosimilitud de la información que circula por las redes sociales podemos señalar dos causas. En primer lugar, los usuarios generan una mayor credibilidad en las noticias compartidas que reciben a través de un conocido. Mientras se considera que los medios de comunicación son inherentemente tendenciosos, la postura de los usuarios hacia sus contactos está basada, precisamente, en la confianza. En segundo lugar, al público le cuesta más detectar información tendenciosa que procede del cálculo algorítmico que llevan a cabo las redes sociales que aquella que resulta de la selección editorial de los medios tradicionales. La existencia de medios tradicionales durante mucho tiempo ha permitido que la sociedad desarrolle métodos para identificar presupuestos ideológicos y sea capaz de distinguir la información verídica de la falsa, de la caricatura o del relato irónico o humorístico. En cambio, las novedosas redes sociales y sus métodos de selección de información no son conocidos. La falta de transparencia de sus algoritmos dificulta que los ciudadanos puedan identificar sus sesgos ideológicos procedentes de las personas que trabajan en las empresas y los usuarios tampoco tienen las indicaciones adecuadas para validar si la información es real o no.

El principal efecto de los filtrados personalizados de información en función de nuestros gustos personales es que la versión del mundo que encontramos a diario solo sirve para confirmar y reafirmarnos en nuestras creencias preexistentes gracias a la limpieza invisible a la que ha sido sometida. En 2011 se acuñó el término filter bubble $e^{12}$ que podríamos traducir por «burbuja (de información) filtrada» para aludir a esta realidad y se comprobó con la función de búsqueda personalizada de Google que impide que dos personas jamás encuentren la misma información aunque empleen los mismos términos en su búsqueda. Esas fórmulas deciden lo que es visible para nosotros y lo que nos va a permanecer oculto limitando nuestro conocimiento de un más amplio abanico de ideas e información fidedigna y condicionando el descubrimiento casual de otras fuentes de conocimiento. Si el algoritmo suprime las fuentes diversas, e incluso contradictorias, de información —esto es, aquellas que retan a nuestras convicciones personales - se corre el riesgo de que aumente hasta el extremo la separación de los diversos puntos de vista sociales, creando grupos sociales realmente divergentes.

A mayor abundamiento, los algoritmos de filtrado ya demostraron no ser capaces de evaluar y diferenciar la calidad o fiabilidad de las noticias. Cabe recordar el frustrado experimento de Facebook tras recibir denuncias que la acusaban de imprimir un sesgo tendencioso a la selección de noticias. En un afán de neutralidad, la empresa despidió a los dieciocho editores responsables de la clasificación de noticias

12 La obra seminal sobre este temática es la de PARISER, E., The Filter Bubble: What the Internet is hidding from you, Penguin Press, New York, 2011. 
siendo sustituidos por algoritmos solo para descubrir en un breve periodo de días que estos no eran capaces de distinguir entre noticias verdaderas y noticias falsas ${ }^{13}$.

De este modo, estas redes sociales y sus algoritmos no solo no limpian el universo de la comunicación de mentiras sino que amplifican la difusión de este contenido peligroso a la vez que reducen la visión del mundo. Es lo que ha descrito como «el poder social de los algoritmos» ${ }^{14}$. Redes sociales que disfrutan de un poder inmenso porque controlan «quién publica qué y lo comparte con quién, y cómo se rentabiliza esa publicación $»^{15}$. Todas estas compañías cuentan con plataformas que permiten a los medios la publicación de contenido directo y exclusivo dentro de la red social que puede ser compartido por los usuarios ${ }^{16}$ pero apenas sabemos nada de cómo estas redes sociales seleccionan sus noticias puesto que el trabajo interno de estos sistemas no es transparente al no estar sometidos a ningún tipo de regulación externa.

De ahí que si bien en su nacimiento estas empresas tecnológicas no se construyeron con la intención de asumir responsabilidades en el terreno de la libertad de prensa, cada vez juegan un papel más relevante en la información social y, como veremos, las soluciones que se están arbitrando en la Unión Europea en la lucha contra las noticias falsas ponen su acento en el compromiso y la colaboración de estos operadores.

\section{LA REACCIÓN DE LA UNIÓN EUROPEA Y LOS ESTADOS MIEMBROS ANTE LA PROLIFERACIÓN DE NOTICIAS FALSAS}

La búsqueda de respuestas a los peligros que las noticias falsas plantean para la democracia está desarrollándose desde muchos frentes. En Estados Unidos, la actividad de verificación de datos en los medios alcanzó una cota febril durante la campaña electoral presidencial aunque en este país la lucha contra las noticias falsas es especialmente difícil debido a la protección que la Primera Enmienda de la Constitución concede a la libertad de expresión ${ }^{17}$.

Yendo al contexto de la Unión Europea no hay gobierno que no tema el efecto que la proliferación de estas noticias inventadas con apariencia de

13 «Facebook despide a sus editores y el algoritmo se vuelve loco», El Confidencial, 31 de agosto de 2016 y «Facebook has repeatedly trended fake news since firing its human editors», The Washington Post, 16 de octubre de 2016.

14 RAINIE, L. y ANDERSON, J., «Code-Dependent: Pros and Cons of the Algorithm Age», Pew Research Center, Febrero 2017, p. 25 y BEER, D., «The social power of algorithms», Information, Communication E Society, 20/1, 2017, pp. 1-13.

15 BELL, E., «Facebook se está comiendo el mundo», Cuadernos de Periodistas, 32, 2016, p. 68.

16 Se trata de Discover App lanzada por Snapchat, Instant Articles por Facebook, Apple News y Accelerate Mobile Pages por Apple y Google respectivamente y Moments por Twitter.

17 Sobre la libertad de expresión en Internet a la luz de la Primera Enmienda, véase ROSEN, J., «The Delete Squad. Google, Twitter, Facebook and the global battle over the future of free speech», New Republic, 29 de abril de 2013. 
información veraz pueda tener en el discurrir de los acontecimientos políticos, especialmente si hay elecciones a la vista. Por ello, organismos y poderes públicos tanto a nivel nacional como europeo se han involucrado en la lucha contra las mentiras y lo han hecho apostando por un modelo que apunta tanto a la regulación como a la colaboración de las industrias implicadas mediante el desarrollo de sistemas de filtrados y la responsabilidad de los usuarios para que decidan críticamente los contenidos que consumen ${ }^{18}$.

Entre los países que se han decidido por la opción regulatoria destaca Alemania cuyo Gobierno presentó en marzo de 2017 un proyecto de ley que prevé multas de hasta 50 millones de euros a las redes sociales que no eliminen contenidos difamatorios, mensajes de odio o noticias falsas. Por su parte, el presidente de Francia, Emmanuel Macron, ha anunciado en enero de 2018 que promoverá una ley para luchar contra la proliferación de noticias falsas a lo largo del periodo electoral. También en Italia se ha presentado una propuesta de ley para prevenir la manipulación de la información online, garantizar la transparencia en la web e incentivar la alfabetización mediática que incluye condenas civiles y penales para quienes difundan noticias exageradas o tendenciosas que incluyan datos o hechos manifiestamente infundados o falsos. En España, el Gobierno ha incluido las noticias falsas como amenaza en la Estrategia de Seguridad Nacional 2017.

Por su parte, la Unión Europea también ha presentado algunas propuestas de reformas para contrarrestar la desinformación, reformas que cabe resumir como sigue:

Primero, fortalecer la iniciativa East Stratcom creada por el Consejo europeo en marzo de 2015 para combatir la campaña rusa de desinformación mediante un equipo de 400 voluntarios que cada semana publica dos boletines que ponen al descubierto las mentiras que el Kremlin quiere hacer pasar por verdades en Europa. Junto con esta iniciativa, se reclama incluir la lucha contra las informaciones falsas en la agenda política de seguridad.

Segundo, desafiar públicamente a quienes difunden la desinformación y que los Estados apoyen equipos de evaluadores o fact-checkers independientes. En España, El Confidencial o La Sexta llevan tiempo desarrollando esta herramienta de la verificación de datos (fact-checking en inglés) con fórmulas donde combinan la actividad de contraste periodístico con la imagen a través de la televisión ${ }^{19}$.

18 Sobre la dinámica reguladora de contenidos en Internet recomendamos el interesante trabajo de TERUEL LOZANO, G. M., «Libertad de expresión en Internet, control de contenidos de las páginas web y sus garantías constitucionales», Revista Aranzadi de Derecho y Nuevas Tecnologías, 25, 2011, pp. 81-103.

19 La tendencia periodística del fact-checking llegó a España en 2013 con el programa El Objetivo de La Sexta, en concreto, con la sección «Pruebas de verificación» en la que se comprobaban las manifestaciones más reiteradas de la vida pública. Sobre el tema, HERNÁNDEZ, N., «Estos son los datos, suyas las conclusiones» y ECHEVARRÍA, B., «Más 'fact-checking' contra la posverdad», ambos en Cuadernos de Periodistas, 33, 2017, pp. 9-16 y pp. 17-20, respectivamente. 
Tercero, combatir la propaganda y la desinformación con información real. Esta reacción no es novedosa puesto que se lleva haciendo no solo desde los medios tradicionales sino utilizando herramientas digitales en la línea de lo que hacen páginas web como FactCheck, PolitiFact o Snopes.

Cuarto, y muy destacadamente, se reclama la adopción de un compromiso europeo similar al seguido en la lucha contra la propagación de mensajes de odio a través de las redes sociales. Se trataría de aprobar medidas a nivel comunitario siguiendo el ejemplo establecido por el Código de conducta propuesto por la Comisión en el ámbito de la lucha contra los mensajes que fomentan el odio, el racismo y la xenofobia a través de la $\operatorname{Red}^{20}$ al que se adhirieron Facebook, Twitter, Youtube y Microsoft a finales de mayo de 2016.

En esta dirección, no sería la primera vez que los gigantes de la Red comparten una iniciativa para rastrear contenidos ilícitos en sus redes. Con anterioridad, las cuatro compañías tecnológicas Twitter, Facebook, YouTube y Microsoft suscribieron un acuerdo para compartir información y una plataforma para identificar imágenes de abusos infantiles en Internet. El siguiente paso ha sido el de colaborar con una base de datos que localice y suprima el contenido extremista de las redes, esto es, los vídeos e imágenes que promueven el terrorismo. El objetivo es que los grupos terroristas no empleen las redes como amplificador a nivel universal. En otros casos, la implicación de los operadores de Internet en la detección y erradicación de contenidos ilegales es una obligación derivada del cumplimiento de diversa normativa europea y nacional en materia de derechos de autor y propiedad intelectual ${ }^{21}$, derecho a la protección de datos ${ }^{22} \mathrm{o}$ derechos al honor, intimidad y propia imagen ${ }^{23}$,

20 Código de conducta contra el discurso ilegal del odio a través de Internet, cit. Los resultados de la aplicación de este Código entre octubre y noviembre de 2016 se han publicado en un primer análisis con conclusiones decepcionantes a juicio de la Comisión. El contenido del informe disponible en http://www.politico.eu/ wp-content/uploads/2016/12/factsheet-code-conduct.pdf.

21 Directiva 2000/31/CE del Parlamento Europeo y del Consejo, de 8 de junio de 2000, relativa a determinados aspectos jurídicos de los servicios de la sociedad de la información, en particular el comercio electrónico en el mercado interior; Directiva 2001/29/CE del Parlamento Europeo y del Consejo, de 22 de mayo de 2001, relativa a la armonización de determinados aspectos de los derechos de autor y derechos afines a los derechos de autor en la sociedad de la información y Directiva 2004/48/CE del Parlamento Europeo y del Consejo, de 29 de abril de 2004, relativa al respeto de los derechos de propiedad intelectual. En nuestro país, Real Decreto Legislativo 1/1996, de 12 de abril, por el que se aprueba el texto refundido de la Ley de Propiedad Intelectual así como Ley 34/2002, de 11 de julio, de servicios de la sociedad de la información y de comercio electrónico. Sobre el tema, PAUNER CHULVI, C., «Los medios de comunicación digitales y los agregadores de noticias: ‘la tasa Google restringe la libertad de información?», Estudios sobre Propiedad Intelectual, A. Fayos (ed.), Dykinson, 2016, pp. 229-244.

22 Directiva 95/46/CE del Parlamento Europeo y del Consejo, de 24 de octubre de 1995, relativa a la protección de las personas físicas en lo que respecta al tratamiento de datos personales y a la libre circulación de estos datos, Reglamento 679/2016, del Parlamento Europeo y del Consejo, de 27 de abril de 2016, relativo a la protección de las personas físicas en lo que respecta al tratamiento de datos personales y a la libre circulación de estos datos, por el que se deroga la Directiva 95/46/CE y Ley Orgánica 15/1999, de 13 de diciembre, de Protección de Datos de Carácter Personal.

23 Artículo 8 CEDH y artículo 7 CDFUE. En España, Ley Orgánica 1/1982, de 5 de mayo, de protección civil del derecho al honor, a la intimidad personal y familiar y a la propia imagen y Ley Orgánica 10/1995, de 23 de noviembre, del Código Penal. 
etc. Ahora bien, la traslación de este modus operandi a la erradicación de las noticias falsas exige alguna reflexión puesto que no siempre nos hallamos, en sentido estricto, ante contenidos ilícitos sino ante contenidos dañinos o nocivos.

\section{LAS REDES SOCIALES ANTE EL FENÓMENO DE LAS NOTICIAS FALSAS: SOLUCIONES PROPUESTAS}

La estrategia colaborativa para luchar contra las noticias falsas en Europa ha cristalizado, por tanto, en la demanda de los poderes públicos hacia las empresas tecnológicas solicitando su implicación aunque esta pretensión no contó con la aceptación inmediata de las industrias implicadas. De hecho, las empresas tecnológicas y muy particularmente, Facebook como la fuerza más poderosa y fuente de acceso primario de información, rechazaron hasta hace poco su naturaleza de medios de comunicación mostrándose reacias a asumir su responsabilidad en el control de la información que publican y prefieren presentarse como intermediarios neutrales dedicados a ofrecer «la mejor experiencia» a su «comunidad». Pero, a la vez, el hecho de servir de plataforma para la difusión de informaciones ha provocado que Facebook se tenga que enfrentar a problemáticas relacionadas con la veracidad, la privacidad, la edición y difusión de contenidos, esto es, con cuestiones relacionadas con la libertad de expresión e información y su circulación por la Red.

Desde nuestro punto de vista, entendemos que los gigantes de Internet, como prestadores de servicios de la información, sí tienen responsabilidades que derivan de su inmenso poder informativo y no pueden ser considerados estrictamente como compañías tecnológicas neutrales. Cuando un término de búsqueda da resultados diferentes en función del historial de búsquedas, del navegador que se usa o de la ideología y gustos del usuario hay, sin lugar a dudas, una toma de decisión subyacente y la plataforma está tomando partido por un modo concreto de «servir» las noticias lo que es, en última instancia, una decisión informativa. Esto es lo que ha llevado a que, tímidamente, Facebook haya aceptado desde finales de 2016 un nuevo tipo de responsabilidad que consiste en la creación de un espacio en el que la gente pueda informarse de manera segura y acreditada. En esta posición intermedia se acepta que la red social no puede convertirse en un «árbitro de la verdad» pero sí en un socio indispensable en la lucha contra los bulos manifiestos.

Esta aceptación de responsabilidad no es lo mismo que clasificar a las redes sociales como editores. En sentido estricto, las empresas no «publican» nada pero son parte de lo que se ha denominado como «la infraestructura de la libertad de expresión» y como tal, Facebook, Twitter y Google tienen responsabilidades cívicas y democráticas. Esta responsabilidad se concreta en un deber de colaboración para impedir la propagación de las de noticias falsas partiendo siempre de un principio de transparencia, esto es, la obligación de explicar cómo funcionan sus algoritmos y cómo seleccionan las noticias que se van a ver. 
Así, los prestadores de servicios en Internet han comenzado a implementar algunos mecanismos de filtrado y bloqueo de contenido como primer paso en la lucha contra las noticias falsas. Estos sistemas de filtrado han sido considerados el remedio equilibrado para preservar la libertad de expresión frente a los contenidos nocivos en Internet. Lo cierto es que, con frecuencia, el filtrado viene determinado por las condiciones impuestas a los usuarios cuando contratan o utilizan el servicio como es el caso de las «normas comunitarias» en las redes sociales que pueden eliminar contenidos ilegales así como aquellos que consideran inapropiados o contrarios a la imagen de la empresa como parte de su política comercial. Pero esta iniciativa privada viene ahora promovida por los mismos poderes públicos quienes imponen a los prestadores de servicios el uso de filtros para controlar e identificar determinados contenidos, bloquearlos y, en su caso, retirarlos.

En esta línea, las soluciones concretas que están implementando las redes sociales en la lucha contra las noticias falsas gravitan en torno a tres opciones e, incluso, la combinación de todas ellas: uno, el reclutamiento de un grupo humano de revisores o editores especialmente procedentes de los medios de comunicación tradicionales; dos, una estrategia colaborativa y tres, soluciones tecnológicas basadas en algoritmos.

Por lo que se refiere a las soluciones humanas se trataría de la incorporación de profesionales capacitados para realizar la verificación de hechos, terceros independientes que intervendrán en la selección y confrontación de informaciones antes de entrar en el flujo de noticias de las redes. La verificación sistemática de datos y hechos en la esfera pública se considera una herramienta elemental para el ejercicio del buen periodismo y ha formado parte de la esencia del trabajo en las redacciones de la prensa tradicional desde donde se ha exportado a otros medios de comunicación (audiovisual y online) hasta convertirse en una tendencia mundial.

Los partidarios de esta propuesta defienden que el juicio humano es más confiable que las soluciones tecnológicas o algoritmos que pueden tener dificultades para detectar mensajes provocadores, irrelevantes o sin relación con la noticia en una comunidad en línea (los conocidos como trolls) o distinguir matices cuando se enfrentan al ejercicio de la libertad de expresión. Por el contrario, las desventajas de esta sugerencia son, en primer lugar, de naturaleza económica ya que el ecosistema de las redes sociales es enorme y la contratación de suficiente personal que actúe con rapidez y eficacia supone un desembolso económico muy elevado. En segundo lugar, los evaluadores también son parciales y subjetivos y deberán especificarse los criterios que se emplearán para decidir el carácter verdadero o falso de una noticia.

En cuanto a las soluciones colaborativas (crowdsourcing en inglés) se trata de abrir el proceso de evaluación de las noticias a los usuarios de las redes permitiéndoles calificarlas según su criterio. El etiquetado de las noticias deja libertad al usuario para decidir si les otorga o no credibilidad. El crowdsourcing es un proceso de construcción voluntaria similar al que sigue Wikipedia y es menos probable 
que pueda ser acusado de parcialidad o censura porque está abierto teóricamente a todo el mundo. Sin embargo, también es susceptible de ser manipulado por grupos de personas que promuevan las mismas noticias falsas o tendenciosas.

En relación con las soluciones basadas en algoritmos se trata de fórmulas que trabajan a partir de la constatación de que muchas fábricas de noticias falsas consiguen etiquetarlas con metadatos que son atractivos para los algoritmos que seleccionan y priorizan las noticias que vamos a ver en las redes sociales en primer lugar. Por ello se procede a modificar esos algoritmos de selección de noticias de forma que otorguen mayor peso a las páginas consideradas más fiables y hagan menos visibles los contenidos de baja credibilidad.

Aunque las compañías tecnológicas afirman que los algoritmos están libres de sesgo ideológico es incuestionable que no son necesariamente equitativos puesto que quienes los crean definen su funcionamiento y sus resultados. Las ventajas de esta opción son su bajo coste económico y la facilidad de su implementación.

Esta ofensiva de las grandes tecnológicas contra las noticias falsas se ha visto complementada por las empresas de compra programática de publicidad quienes también aplican operaciones de filtrado a través de una clasificación en sistemas de listas blancas y negras de portales de noticias fiables y otros de contenido problemático ${ }^{24}$. Esta iniciativa pretende garantizar a los anunciantes que no invierten en medios de comunicación que difunden informaciones falsas.

La situación es delicada ya que si bien las noticias falsas contaminan a la opinión pública y pueden poner en peligro al propio sistema democrático, las soluciones que se sugieren podrían calificarse de información tendenciosa - la política o sesgo ideológico de una empresa privada incorporado en un algoritmo- o incluso censura, ambas muy dañinas para la democracia que depende del ejercicio de la libertad de expresión e información.

\section{LOS SISTEMAS DE FILTRADO Y LAS GARANTÍAS CONSTITUCIONALES DE LA LIBERTAD DE EXPRESIÓN E INFORMACIÓN}

El control de los contenidos informativos que circulan por la Red es una cuestión problemática que nos enfrenta, básicamente y en primer término, a la cuestión de la definición de los límites a la libertad de expresión e información en

24 La compra programática consiste en la utilización de sistemas automatizados para la difusión de anuncios de publicidad online y marcas. Esta herramienta permite que los espacios publicitarios se subasten en tiempo real sobre la base de la actividad, los clics y las búsquedas de los usuarios. Si el resultado se ajusta con el público que será el futuro consumidor de la marca, esta se anuncia allí indistintamente del contexto. Empresas como AppNexus o RocketFuel han elaborado este tipo de listas negras de portales web que consideran incitadores del odio o transmisores de información falsa y no los ofrecen a las marcas. A la inversa, existen listas blancas en las que se incluyen medios aprobados por los anunciantes. 
el entorno digital. En principio, la difusión de información y opiniones a través de Internet se considera un ejercicio de las libertades de expresión e información y aquellas páginas web que publican contenidos informativos a través de la Red están protegidas por estas libertades y sometidas a sus límites de la misma forma que lo están los medios tradicionales. Es necesario, por tanto, diferenciar entre los tipos de contenido excesivos o ilegítimos ${ }^{25}$. Por un lado, encontramos los contenidos ilícitos que al constituir una infracción legal están prohibidos y son rechazados mediante los procedimientos legalmente establecidos y, por otro lado, están los contenidos nocivos o dañinos que pueden resultar perjudiciales por atentar contra valores o principios y cuya difusión podrá ser limitada o restringida de forma proporcionada. Las noticias falsas son, en este sentido, contenido nocivo que pone en riesgo el pluralismo informativo y defraudan el derecho del público a recibir una información veraz por lo que entendemos que son perfectamente arbitrables algunas medidas limitativas sobre aquellos que las difundan.

En segundo término, es necesario determinar cuál debe ser la implicación y responsabilidad de las redes sociales en la lucha contra el fenómeno de las noticias falsas. Aquí hemos de reflexionar sobre el papel —y el poder- que puede otorgarse a estas empresas privadas y la aptitud de las herramientas que se han implementado en sus procesos de evaluación y selección de las noticias. Así, los intentos de frenar las noticias falsas mediante el filtrado y la retirada de contenidos plantean la cuestión del establecimiento de una especie de censura derivado del interés por difundir la «verdad» fijando una realidad oficial y provocando la correlativa restricción de la libertad de expresión. Una afectación que procede de los prestadores de servicios de Internet quienes, como empresas privadas, «no están en condiciones de ponderar derechos y bienes jurídicos adecuadamente, porque se rigen por las reglas de mercado» ${ }^{26}$.

\section{La diferencia entre noticias falsas y otro tipo de manifestaciones}

Ciertamente, invocar a la verdad como criterio absoluto puede ser un enemigo de la libertad de expresión e información puesto que el concepto de verdad es ajeno a la perspectiva jurídica. Esta libertad, consagrada en textos internacionales como el artículo $10 \mathrm{CEDH}$, integra la libertad de opinión, por un lado, y la de recibir o comunicar informaciones, por otro. No obstante, el tratamiento que reciben ambas libertades no es igual ya que los hechos son susceptibles de prueba y se les puede exigir el requisito de veracidad mientras que las opiniones no pueden ser comprobadas ni, por ello, sometidas al control de la veracidad (STEDH

25 Seguimos a FERNÁNDEZ ESTEBAN, M. L., «Internet y los derechos fundamentales», Anuario Jurídico de La Rioja, 6-7, 2000-2001, pp. 334-335.

26 DE MIGUEL BÁRCENA, J., «Las transformaciones del derecho de la información en el contexto del ciberperiodismo», Revista de Estudios Políticos, 173, 2016, p. 159. 
de 15 de marzo de 2011, caso Otegi Mondragón contra España, par. 53). Pero hasta en aquellos supuestos en los que se esté ejercitando la libertad de expresión «a las opiniones ha de exigírseles que se realicen con criterio o, al menos, con sinceridad. Asimismo, incluso cuando una declaración equivale a un juicio de valor (...) debe tener suficiente base factual — coincidencia con el referente externo- - sin lo cual sería excesiva.» (STEDH de 27 de febrero de 2001, caso Jerusalén contra Austria, par. 43).

Estos mismos parámetros en la protección de la libertad de expresión y del derecho a la información son compartidos por el TJUE y nuestro Tribunal Constitucional. Por lo que se refiere al TJUE, este Tribunal ha construido su posición sobre las libertades de opinión y prensa dentro de los límites marcados por el artículo 51 CDFUE que ciñe su interpretación a aquellos supuestos en los que se estén ejerciendo competencias de la Unión o se esté en el ámbito de la aplicación del Derecho europeo ${ }^{27}$. El Tribunal de Luxemburgo repite la mecánica interpretativa del TEDH en relación con las libertades del artículo 11 de la CDFUE que reproduce en términos idénticos el contenido del artículo 10 del $\mathrm{CEDH}$ - aplicando a las restricciones de las libertades de comunicación el test de necesidad y proporcionalidad ${ }^{28}$.

El mismo enfoque es aplicable al reconocimiento de las libertades de expresión e información consagradas en el artículo 20 CE y a la interpretación realizada por el TC. Desde sus primeras sentencias, el Alto Tribunal ha mantenido una línea jurisprudencial homogénea en la que su afirmación clave sobre el contenido de la noción «información veraz» es que veracidad no equivale a «verdad», sino que «lo que ampara el art. 20.1 d) es la información rectamente obtenida y difundida, aun cuando su total exactitud sea controvertible» (STC 121/2002, de 20 de mayo, fj 5). Frente a una postura objetivista de la información que solo admitiría una versión incontestable de los hechos, para el Tribunal Constitucional «las afirmaciones erróneas son inevitables en un debate libre, de tal forma que de imponerse la verdad como condición para el reconocimiento del derecho, la única garantía de la seguridad jurídica sería el silencio» (STC 6/1988, de 21 de enero, fj 5) porque «la limitación del derecho a la información al relato puro, objetivo y aséptico de hechos no resulta constitucionalmente aceptable ni compatible con el pluralismo, la tolerancia y la mentalidad amplia, sin los cuales no hay «sociedad democrática» (STEDH de 7 de diciembre de 1976, caso Handyside, par. 65), pues la divergencia subjetiva de opiniones forma parte de la estructura misma del aspecto institucional del derecho a la información». Pero tampoco puede concluirse que la información sea una cuestión puramente subjetiva basada en la

27 LINDE PANIAGUA, E., «El ámbito de aplicación: el talón de Aquiles de la Carta de Derechos Fundamentales de la Unión Europea», Revista de Derecho de la Unión Europea, 15, 2008, p. 39.

28 Sobre casos recientes en los que el juez europeo se aparta de los clásicos test del artículo 10 del Convenio, véase RODRÍGUEZ-IZQUIERDO SERRANO, M., «La libertad de expresión y la jurisprudencia del Tribunal de Justicia de la Unión Europea», Estudios de Deusto, 2, 2014. 
mera creencia subjetiva del informador de que lo que afirma es verdad. Así, no es información ni noticia aquella narración que defrauda al interés colectivo o que carece de un fin informativo, como los rumores, insidias, insultos o vilipendios (STC 214/1991, de 11 de noviembre, fj 6) y no cabe otorgar protección constitucional, aún cuando hubieren sido emitidas con finalidad informativa, «a las narraciones falsas o tendenciosas, las realizadas con fin de infamar, las que revelan la intimidad de las personas o las que vulneran principios y bienes jurídicos como la buena fe, la seguridad del Estado o el buen funcionamiento de las instituciones públicas» (STC 51/1985, de 10 de abril) ${ }^{29}$.

Esta construcción jurisprudencial enmarca claramente el alcance de qué debe entenderse por noticia falsa y su diferenciación de otros términos. Así, una opinión puede resultar acertada o no pero nunca podrá ser «falsa» porque las apreciaciones o juicios de valor no se prestan a una demostración de exactitud, por mucho que alguien pueda no estar de acuerdo con ellas. También las noticias partidistas que interpretan los hechos conforme a criterios ideológicos muy marcados son ejemplos de mala praxis periodística pero no ejercicios ilegítimos de la libertad de expresión. Igualmente, las parodias y bromas o la sátira pueden contener afirmaciones erróneas o inciertas y, en este sentido, ser «falsas» pero el mismo contexto irónico o humorístico descarta que lo afirmado pueda ser catalogado como noticia.

Las únicas noticias falsas son aquellas informaciones ficticias o fraudulentas que se difunden a sabiendas de su inexactitud. Esta definición introduce el elemento de «deshonestidad» que resulta muy útil para discriminar las noticias falsas e inaceptables de aquellas otras informaciones que contienen errores y que, como vimos, pueden gozar de protección constitucional. En resumen, se trata de realizar una evaluación de calidad e impedir que páginas creadas con la única finalidad de introducir historias inventadas, informaciones no contrastadas, simples rumores o puras invenciones para obtener ingresos económicos puedan ser detectadas y etiquetadas o, incluso, retiradas del entorno comunicativo y sea posible detener el impulso viral que adquieren.

Obviamente, la identificación de las noticias falsas no es un proceso automático y, tratándose de un término ambiguo, un escollo muy importante es la dificultad de establecer un marco regulatorio europeo - no digamos internacional- en el que se fije qué es una noticia falsa para el conjunto de los países de la UE a la luz de las notables diferencias que existen entre ellos a la hora de definir el contenido y alcance de esta libertad que son particulares en cada Estado y tienen un componente cultural muy fuerte. Así, el límite entre noticias falsas y libertad de expresión no será igual para los gobiernos de países cada vez más

29 AZURMENDI ADARRAGA, A., «De la verdad informativa a la 'información veraz’ de la Constitución Española de 1978. Una reflexión sobre la verdad exigible desde el derecho de la información», Comunicación y Sociedad, 2, 2005, p. 20. 
autoritarios como Polonia y Hungría que para la Comisión Europea o Alemania, por citar solo algunos ejemplos.

Pero también es cuestionable la eficacia de las soluciones algorítmicas para extractar las noticias falsas de aquel otro tipo de manifestaciones protegidas por el ejercicio de la libertad de expresión (opiniones, sátira,...) entre todo el flujo de información que inunda la Red sin aumentar la amenaza de la censura en Internet.

\section{La responsabilidad de las redes sociales en la distribución de noticias falsas}

Los responsables de clasificar y etiquetar la información que los usuarios vamos a leer son las propias redes sociales quienes diseñan los mecanismos de filtrado y bloqueo de contenidos basados en algoritmos. Si bien los usuarios saben que el primer principio que incluye Facebook en sus normas comunitarias es que «Todo el mundo debería tener la libertad de compartir la información que quiere (...)», nadie desconoce que el algoritmo de esta red social filtra cantidades enormes de datos — como los comentarios de sus usuarios- para comprobar y decidir si el contenido es apropiado. El algoritmo puede, por ejemplo, estar programado para descartar textos que contienen insultos o los que proceden de una parte del mundo y repetidamente solicitan que se facilite una cuenta bancaria. Pero estos estándares insertados en la tecnología de la empresa no son transparentes para la mayoría de la población ni tampoco son estáticos sino se actualizan y modifican frecuentemente lo que aviva el temor al establecimiento de una especie de censura procedente de un poder privado y sin contar con los propios usuarios. En principio, el concepto constitucional de censura previo que prevé el artículo 20.2 CE no se adapta al filtrado y posterior bloqueo o retirada de contenidos en Internet puesto que estas acciones se producen una vez la publicación se ha realizado y no proceden de órganos estatales pero lo cierto es que, como la doctrina ha señalado, sí atentan contra el derecho de los ciudadanos a acceder a la información en $\operatorname{Red}^{30}$ y pueden desembocar en un efecto disuasión o chilling effect ${ }^{31}$.

Precisamente, el TJUE ha rechazado el establecimiento de sistemas genéricos de filtrados por resultar contrarios al reconocimiento de la libertad de expresión. Así, algunos pronunciamientos del Tribunal de Luxemburgo han puesto en entredicho la eficacia del sistema de filtrado para diferenciar entre contenidos

30 TERUEL LOZANO, G. M., «La libertad de expresión y censura en Internet», Estudios de Deusto, 62/2, 2014, p. 63

31 Por este motivo, Josu de Miguel reivindica una adaptación redefinición del concepto constitucional de censura previa prevista en el art. 20.2 CE para su adaptación a los nuevos riesgos del avance tecnológico (DE MIGUEL BÁRCENA, J., «Las transformaciones del derecho de la información en el contexto del ciberperiodismo», cit., p. 160). 
lícitos e ilícitos en relación con los derechos de autor y la consiguiente vulneración de la libertad de información. Se trata de la saga de sentencias SABAM que han declarado contraria al artículo 11.1 de la CDFUE la aplicación concreta de un sistema de filtrado realizado en Bélgica mediante orden judicial para salvaguardar derechos de propiedad intelectual ${ }^{32}$. El TJUE ha subrayado la necesidad de armonización de los distintos derechos fundamentales protegidos por la Carta y habla de un justo equilibrio, exigido por el artículo 52 de la Carta, que permite que, por una parte, se adopten medidas de bloqueo sin que las mismas puedan, por otra parte, llegar a ser privativas del derecho a acceder a información lícita por parte de los usuarios de Internet ${ }^{33}$.

Esta posición no descarta de manera absoluta la posibilidad de utilizar sistemas de filtrado de contenidos pero sí obliga a que se trate del bloqueo de contenidos precisos y en base a parámetros claros, predeterminados y objetivamente justificables que rijan cualesquiera medidas para restringir el contenido de terceros que vaya más allá de los requisitos legales ${ }^{34}$. Lo que nos lleva a la condición clave: la necesidad de transparencia en los procesos de evaluación y selección de las noticias que se difunden. Los intermediarios están obligados a facilitar información sobre el funcionamiento de sus algoritmos porque, en última instancia, están afectando al derecho de acceso a la información y debemos tener acceso a la fiscalización de ese poder.

De hecho, la importancia y aumento del número de decisiones que se toman aplicando algoritmos ha llevado a que el nuevo Reglamento Europeo de Protección de Datos restrinja las decisiones individuales automatizadas, incluyendo la elaboración de perfiles, que afecten significativamente a los usuarios (artículo 22 REPD) y crea un «derecho a la explicación» que asegura que el ciudadano pueda reclamar una explicación sobre cualquier decisión automatizada que le afecte.

Esta necesidad de conocer cómo funciona el algoritmo es trasladable al ámbito de la comunicación porque como principio básico la transparencia es una regla imprescindible para confiar en la información y el periodista, el elemento más importante para elaboración de una ciencia de la verificación ${ }^{35}$.

Como hemos visto anteriormente, hay que ser conscientes de que un algoritmo, por definición, nunca va a ser capaz de distinguir lo verdadero de lo falso y que no es posible diseñar un «algoritmo de la verdad» aunque puede resultar un instrumento útil si ayuda, por ejemplo, a valorar la calidad de las páginas web de las que surge la noticia en función de la veracidad de los datos

32 SSTJUE C-70/10, Scarlet c. SABAM, de 24 de noviembre de 2011 y C-360/10, Netlog c. SABAM, de 16 de febrero de 2012.

33 STJUE C-314/12, caso Telekabel, de 27 de marzo de 2014.

34 En este sentido se pronuncia el apartado 4.a) de la Declaración conjunta sobre Libertad de Expresión y Noticias Falsas, Desinformación y Propaganda.

35 KOVACH, B. y ROSENSTIEL, T., Los elementos del periodismo, Eds. El País, Madrid, 2012, p. 113. 
que contiene, destacando aquellos datos de las noticias que el usuario ha de contrastar para formarse una opinión o señalando las noticias falsas y contextualizándolas.

Pero esta intermediación de la inteligencia artificial no será suficiente. El algoritmo puede ser un instrumento que debe complementarse, como mínimo, con un equipo humano de verificación. El fact-checking automático y automatizado no puede sustituir a las personas puesto que estas son mejores que la informática para analizar mensajes cargados de contextos, juicios o afirmaciones vagas. Pero la informática tiene la ventaja competitiva de peinar la red, evaluando afirmaciones sencillas. En otras palabras, la informática puede separar lo blanco de lo negro dejando que las personas se centren en los matices del gris. Por eso entendemos que la combinación de fórmulas algorítmicas y equipos humanos de verificación constituyen un montaje adecuado para el cribado de noticias falsas.

De ahí que el avance en las técnicas de verificación que están comenzando a implementarse tanto en medios de comunicación como en las redes sociales deban ajustarse, como mínimo, a los estándares internacionales consensuados en esta materia, enumerados en el Código Internacional de Principios de Verificación de Datos $^{36}$, y que insisten en el mandato de transparencia. Las fórmulas internacionales exigen apartidismo e igualdad en la aplicación de técnicas de fact-checking que implica que se evalúan las reclamaciones bajo el mismo criterio sin centrar los procesos de evaluación en una versión de los hechos; transparencia en las fuentes para que los usuarios sean capaces de verificar, a su vez, los resultados obtenidos; transparencia en los recursos y en quién promueve la iniciativa mediante la publicidad de los fondos recibidos para realizar el trabajo y la trayectoria profesional del personal de verificación; transparencia en la metodología a través de la exposición clara del procedimiento que se emplea para seleccionar, investigar, escribir, editar, publicar y corregir las noticias y honestidad en la publicación de correcciones para que los lectores visualicen las versiones corregidas.

Esta actividad de verificación, por otra parte, no debería finalizar con la eliminación de contenidos sino que lo oportuno sería que los equipos externos o automatizados de fact-checking señalasen las noticias conflictivas. De forma que los usuarios verán una marca y un enlace a la explicación de los verificadores y serán ellos quienes se formen una opinión propia acerca de la noticia. Esto apunta a la necesidad de la alfabetización mediática, esto es, que los usuarios sean capaces de analizar críticamente la información digital o que se pongan nuevas herramientas a su alcance para evaluar las fuentes y la veracidad de las noticias que consumen online, por ejemplo, mediante la trazabilidad de las mismas o manuales de verificación que ayuden a la detección de noticias falsas ${ }^{37}$.

36 http://www.poynter.org/fact-checkers-code-of-principles/

37 Como el manual de verificación elaborado por periodistas expertos de la BBC, Storyful, ABC, Digital First Media y otros especialistas en verificación que contiene versiones adaptadas a distintos contextos informativos. Acceso a los diferentes manuales en http://verificationhandbook.com/ 


\section{CONCLUSIONES}

Durante los últimos dos años ha aumentado la preocupación por una tendencia cada vez más extendida entre el público de desconfiar de las fuentes de información tradicionales, como periódicos o cadenas de radio y televisión, y en su lugar acudir a Internet y consumir la información que llega a través de las redes sociales a pesar de que el origen de las historias no suele estar claro y no es fácil averiguar si los datos son veraces y están contrastados.

El temor a que esta situación lleve al público a consumir propaganda y noticias falsas ha alcanzado su punto álgido tras los resultados de la elección presidencial estadounidense en 2016 puesto que se sugiere que las noticias falsas que circularon en los meses previos fueron determinantes en su desenlace. El creciente fenómeno de las noticias falsas se convierte, de hecho, en una amenaza para la democracia en la medida en que ataca el propio derecho a la libertad de información, el pluralismo y la libertad de los ciudadanos de formarse libremente sus propias opiniones y, en última instancia, socava la confianza en los medios de comunicación en general.

Las noticias falsas son informaciones deliberadamente incorrectas o inciertas y su aparición no es ninguna novedad porque siempre ha habido ejemplos de mal periodismo y manipulación. Lo novedoso es que esas noticias falsas, una vez creadas por fuentes maliciosas, se difunden viralmente a través de las redes sociales y los usuarios las consumen en la creencia de que son fidedignas a pesar de que no se las ha sometido a ningún control de calidad pero han sido compartidas por aquellas personas de su círculo de confianza. De ahí que, en la búsqueda de soluciones para atajar el problema, se ha reclamado la colaboración de las empresas de distribución de contenidos y del mismo modo que ya han aceptado que tienen una responsabilidad social para combatir la piratería online y la difusión de contenido ilegal, se considera necesario que ayuden a redirigir la difusión de las noticias falsas en las redes sociales. En esta línea, las grandes tecnológicas han comenzado a implementar sistemas de filtrado de los contenidos que difunden para su verificación.

Pero estos métodos de control de contenidos por parte de empresas privadas plantean preguntas vitales para la democracia. En primer lugar, la dificultad de determinar con carácter general una definición de noticia falsa puesto que es necesario distinguirla de otras manifestaciones legítimas de la libertad de expresión como pueden ser las bromas o las opiniones partidistas. En segundo término, la posibilidad de que un poder privado limite y pueda afectar de forma determinante y tan generalizada al derecho a la información y a la libertad de expresión. En último lugar, la falta de transparencia que suele acompañar a las fórmulas algorítmicas que las redes sociales aplican para seleccionar - o, en este caso, vetar- las noticias que se difunden.

Entendemos que el reto que plantean las noticias falsas exige un cambio de paradigma no solo en relación con los instrumentos que se habiliten contra ellas sino también en los sujetos implicados en la batalla. 
Por lo que se refiere a los instrumentos, la solución ha de venir de la tarea de verificación. En las sociedades democráticas y libres tiene que estar garantizado el libre flujo de tanta información como sea posible y las restricciones han de reducirse al mínimo lo que sugiere que se evite la sobrerregulación de la Red y muy especialmente, el establecimiento de sanciones penales para combatir las noticias falsas. La verificación, por su parte, ha sido desde siempre el elemento clave en la tarea periodística y puede contribuir a la selección de la información confiable siempre que se conozca el criterio que se aplica y el usuario tenga el control final sobre los contenidos que desea consumir. Esto significa que la colaboración prestada por las empresas tecnológicas en la búsqueda de la verdad informativa puede ser positiva en los términos que se plantean actualmente (diseños tecnológicos, verificación humana y colaboración de los usuarios) siempre que estén presididas por la obligación de transparencia de modo que la sociedad sea consciente de qué fórmula o criterios son los que controlan el flujo informativo al que se nos permite acceder o se prioriza en nuestras redes sociales. Pero, además, el control de contenidos debe finalizar con un etiquetado que sirva de aviso al usuario sobre la baja o nula calidad de la noticia dejando a aquel la libertad de decidir por sí mismo.

En relación con los sujetos, se viene reclamando con acierto la implicación del Estado, los medios de comunicación, las empresas tecnológicas y la sociedad civil. En esta línea destaca la iniciativa de la Plataforma en Defensa de la Libertad de Información que ha presentado un decálogo ${ }^{38}$ que pretende servir de base para consensuar estrategias comunes que combatan la proliferación de las noticias falsas y sus efectos en el periodismo y la sociedad. Estas fórmulas llaman a todos los actores de la cadena informativa a combatir y no fomentar la difusión de noticias falsas para lo que debe alcanzarse una definición consensuada sobre qué debe considerarse bulo o noticia falsa y qué no. En este compromiso coral a los medios les incumbe el deber de informar de la procedencia de los contenidos que elaboran o de los que se hagan eco así como facilitar la trazabilidad de sus informaciones y contenidos. Desde los poderes públicos deberán promoverse campañas de alfabetización mediática y digital que aumenten la capacidad del público para detectar las noticias falsas así como facilitar herramientas que les permita verificar la fiabilidad de su contenido, cabecera o web. Y, finalmente, las empresas de distribución de contenidos deben ser consideradas como empresas informativas en atención al volumen que representan las noticias en su flujo de actividad por lo que han de desarrollar mecanismos que castiguen los bulos, entre otros, con herramientas que permitan filtrarlos del flujo de contenidos compartidos.

38 Plataforma en Defensa de la Libertad de Información, Contra la posverdad: 10 fórmulas para hacer frente a las noticias falsas, 21 de febrero de 2017, http://libertadinformacion.cc/contra-la-posverdad-10-formulas para-hacer-frente-a-las-noticias-falsas/ 
TITLE: Fake news and freedom of expression and information. The control of information contents on the network.

ABSTRACT: The results of the presidential election in the United States or the vote in the United Kingdom to leave the European Union (Brexit) have raised questions about the influence of the fake news originated in web pages created to the effect and quickly disseminated through the social media. As people turn to social networks as a primary news source, the Member States' governments and the EU have requested the collaboration of technology companies to filter out these harmful contents that are threatening to cause misinformation of citizens. In our analysis we reflect on the problems arising from the control of Internet content and, more specifically, what should the legitimate response to disinformation be, what the risks are derived from the imposition of filtering and labelling of information, the possibility of creating a system of private censorship that jeopardizes the pluralism of the network, or the danger of arbitrariness in the construction of the filtering algorithm and its effectiveness in the exercise of freedom of expression in various contexts (such as irony or bumour), among other issues.

Resumen: Los resultados de la elección presidencial en Estados Unidos o el voto en Reino Unido para abandonar la Unión Europea (Brexit) ban suscitado preguntas sobre la influencia de las noticias falsas originadas en páginas web creadas al efecto y difundidas rápidamente a través de las redes sociales. En la medida en que la gente utiliza las redes sociales como fuente principal de información, desde los gobiernos de los Estados miembros y la propia UE se ha solicitado la colaboración de las empresas tecnológicas para filtrar estos contenidos dañinos que amenazan con la desinformación generalizada de la ciudadanía. En el análisis reflexionamos acerca de los problemas derivados del control de los contenidos de Internet y, más concretamente, cuál debe ser la respuesta legítima a la desinformación, cuáles son los riesgos que se pueden derivar de la imposición de filtrado y etiquetado de la información, la posibilidad de encontrarnos ante un sistema de censura privada que ponga en riesgo el pluralismo de la red, o el peligro de arbitrariedad en la construcción del algoritmo de filtrado o su eficacia ante ejercicio de la libertad de expresión en diversos contextos (como la ironía o el bumor), entre otras cuestiones.

KEY WORDS: fake news, freedom of expression and information, social networks, censorship, post-truth, mass media, misinformation.

Palabras Clave: noticias falsas, libertad de expresión e información, redes sociales, censura, posverdad, medios de comunicación, desinformación.

FECHA DE RECEPCIÓN: 14.07.2017

FECHA DE ACEPTACIÓN: 01.02.2018 